\title{
Proportion of Family Physicians Caring for Children is Declining
}

\author{
Aimee R. Eden, PhD, MPH, Zachary J. Morgan, MS, Anuradha Jetty, MPH, and \\ Lars E. Peterson, $M D, P h D$
}

Using data from 2014 to 2018 , we found that the proportion of family physicians caring for children under age 5 years and between ages 5 and 18 years has significantly declined. This has implications for the pediatric primary care workforce and may exacerbate inequities in access to care for pediatric patients in all geographies, particularly those in areas with a shortage of pediatricians. ( $\mathrm{J}$ Am Board Fam Med 2020;33:830-831.)

Keywords: Access to Health Care, Child, Family Physicians, Pediatricians, Primary Health Care

Family physicians (FPs) are trained to provide comprehensive care to their patients-including children of all ages - and are key to ensuring accessible care for all children. ${ }^{1}$ However, previous studies have documented the decline in the percentage of office visits for children to $\mathrm{FPs},{ }^{2}$ the proportion of children seeing FPs for their primary care, ${ }^{3}$ and the proportion of FPs providing care to children of any age. ${ }^{4,5}$ Our objective was to track FP care of children over the past 5 years to assess whether the decline in pediatric care by FPs has continued since the previous study using similar data tracked pediatric care by FPs between 2000 and 2009. ${ }^{4}$

We used 2014 through 2018 data from the American Board of Family Medicine (ABFM) Family Medicine Certification Examination registration questionnaire, which has a $100 \%$ response rate. ${ }^{6}$ From 2014 until 2016, all practicing FPs seeking to continue

This article was externally peer reviewed.

Submitted 4 March 2020; revised 7 April 2020; accepted 11 April 2020.

From the American Board of Family Medicine, Lexington, KY (ARE, ZJM, LEP); Robert Graham Center, Washington, DC (AJ); Department of Family and Community Medicine, College of Medicine, University of Kentucky, Lexington, KY (LEP).

Funding: None.

Conflict of interest: ARE, ZJM, and LEP are employees of the American Board of Family Medicine.

Corresponding author: Aimee R. Eden, PhD, MPH, 1648 McGrathaiana Parkway, Suite 550, Lexington, KY 40511 (E-mail: aeden@theabfm.org).

See Related Article on Page 828. their ABFM certification were asked whether or not they cared for children under age 5 years, ages 5 to 12 years, and ages 13 to 18 years. Starting in 2017, all FPs were asked what percentage of their patient population was under age 5 years and what percentage was between 5 and 18 years. We combined the 5 -to12-year and 13-to-18-year age categories in the 2014 to 2016 data to mirror the 2017 to 2018 categories. We dichotomized the 2017 to 2018 data to reflect any care of children in those age groups, or none, to match the yes/no structure of the 2014 to 2016 data. To capture FPs who provide continuity care across the years of available data, which had different ways of collecting practice setting, we excluded respondents in 2014 to 2016 in likely noncontinuity settings (hospitalist, emergency, etc.) and limited our sample to those stating they provided continuity care in 2017 to 2018. We performed Cochrane-Armitage tests for changes over time. The American Academy of Family Physicians Institutional Review Board approved this study.

We analyzed data from a total of 35,063 FPs over the 5-year period. The proportion of FPs caring for children under age 5 years and age 5 to 18 years declined significantly $(92.5 \%$ to $87.0 \%$ and $76.4 \%$ to $69.4 \%$, respectively), as represented in Figure 1 (both age groups, $P<.001)$. While FPs continued to care for older children at higher rates than younger children over time, the decline was larger in the care of children under 5 (7.0\%) than for 5-to-18-year-olds (5.5\%).

FPs are an important part of the pediatric primary care workforce, particularly for ensuring care accessi- 
Figure 1. Percentage of practicing American Board of Family Medicine Certification Examination candidates providing care to children under age 5 and aged 5 to 18 years, 2014 to $2018(n=35,063)$. Abbreviation: FP, Family physicians.

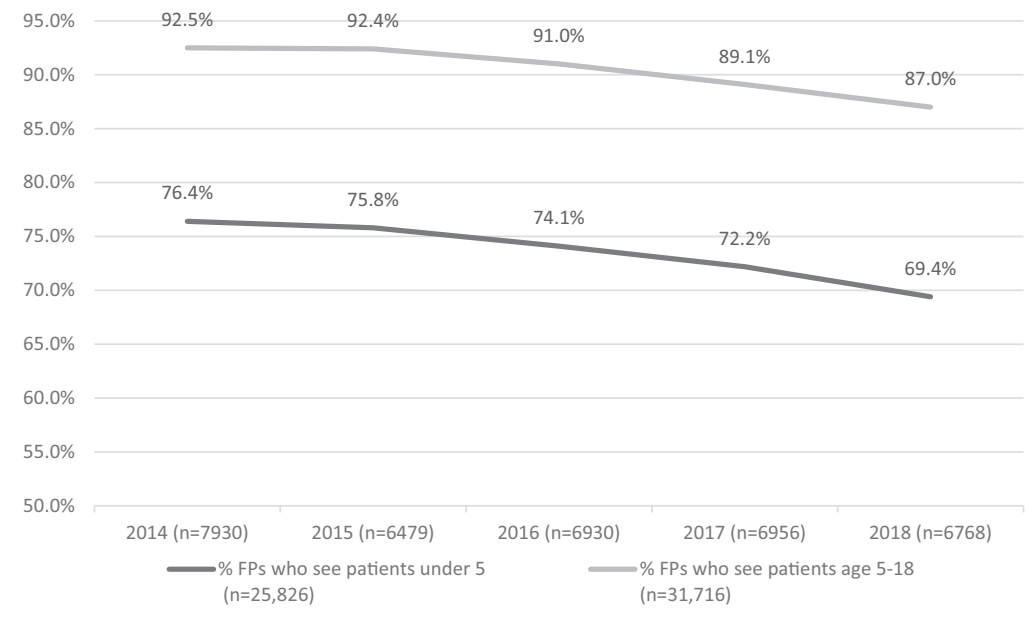

bility for children in rural areas, ${ }^{5}$ and are uniquely positioned to provide comprehensive, continuous care for infants and young children, older children, and adolescent patients, through their transition to adult care. While our percentages are higher than those reported using a different question from 2000 to $2009,{ }^{4}$ we still found a decline in the percentage of FPs caring for both younger and older children, suggesting an underlying shift away from care of children regardless of how that care is measured. The trend does not seem to be related to self reported preparation in residency training, which has been shown to be adequate, ${ }^{7}$ nor to the concurrent decline in prenatal care among FPs. ${ }^{8}$ It is possible that the decline in obstetric care by FPs is associated with the decline in pediatric care,,$^{5}$ particularly care of young children, but this association has not been well documented. While others have speculated about how to reverse this trend in pediatric care, ${ }^{4,5}$ major gaps in evidence exist. To identify appropriate policy solutions, further research is needed to help understand reasons for the decline, whether the decline has any association with patient outcomes, and whether care of children has declined overall or has shifted to pediatricians, nurse practitioners, or physician assistants.

To see this article online, please go to: http://jabfm.org/content/ 33/6/830.full.

\section{References}

1. Shipman SA, Lan J, Chang C, Goodman DC. Geographic maldistribution of primary care for children. Pediatrics 2011;127:19-27.

2. Freed GL, Nahra TA, Wheeler JRC. Which physicians are providing health care to america's children? Trends and changes during the past 20 years. Arch Pediatr Adolesc Med 2004;158:22-6.

3. Wasserman RC, Varni SE, Hollander MC, Harder VS. Change in site of children's primary care: a longitudinal population-based analysis. Ann Fam Med 2019;17:390-5.

4. Bazemore AW, Makaroff LA, Puffer JC, et al. Declining numbers of family physicians are caring for children. J Am Board Fam Med 2012;25:139-40.

5. Makaroff LA, Xierali IM, Petterson SM, Shipman SA, Puffer JC, Bazemore AW. Factors influencing family physicians' contribution to the child health care workforce. Ann Fam Med 2014;12:427-31.

6. Peterson L, Fang B, Phillips R, Avant R, Puffer J. A certification board's tracking of their specialty: the American Board of Family Medicine's data collection strategy. J Am Board Fam Med 2019;32:89-95.

7. Peterson LE, Fang B, Puffer JC, Bazemore AW. Wide gap between preparation and practice of early career family physicians. J Am Board Fam Med 2018;31:174-7.

8. Cohen D, Coco A. Trends in well-child visits to family physicians by children younger than 2 years of age. Ann Fam Med 2010;8:245-8. 